This item was submitted to Loughborough's Research Repository by the author.

Items in Figshare are protected by copyright, with all rights reserved, unless otherwise indicated.

\title{
Diversity and power in the world city network
}

PLEASE CITE THE PUBLISHED VERSION

http://dx.doi.org/10.1016/S0264-2751(02)00020-3

PUBLISHER

(c) Elsevier

VERSION

AM (Accepted Manuscript)

LICENCE

CC BY-NC-ND 4.0

REPOSITORY RECORD

Taylor, Peter J., David R.F. Walker, Gilda Catalano, and Michael Hoyler. 2019. "Diversity and Power in the World City Network". figshare. https://hdl.handle.net/2134/13057. 
This item was submitted to Loughborough's Institutional Repository (https://dspace.lboro.ac.uk/) by the author and is made available under the following Creative Commons Licence conditions.

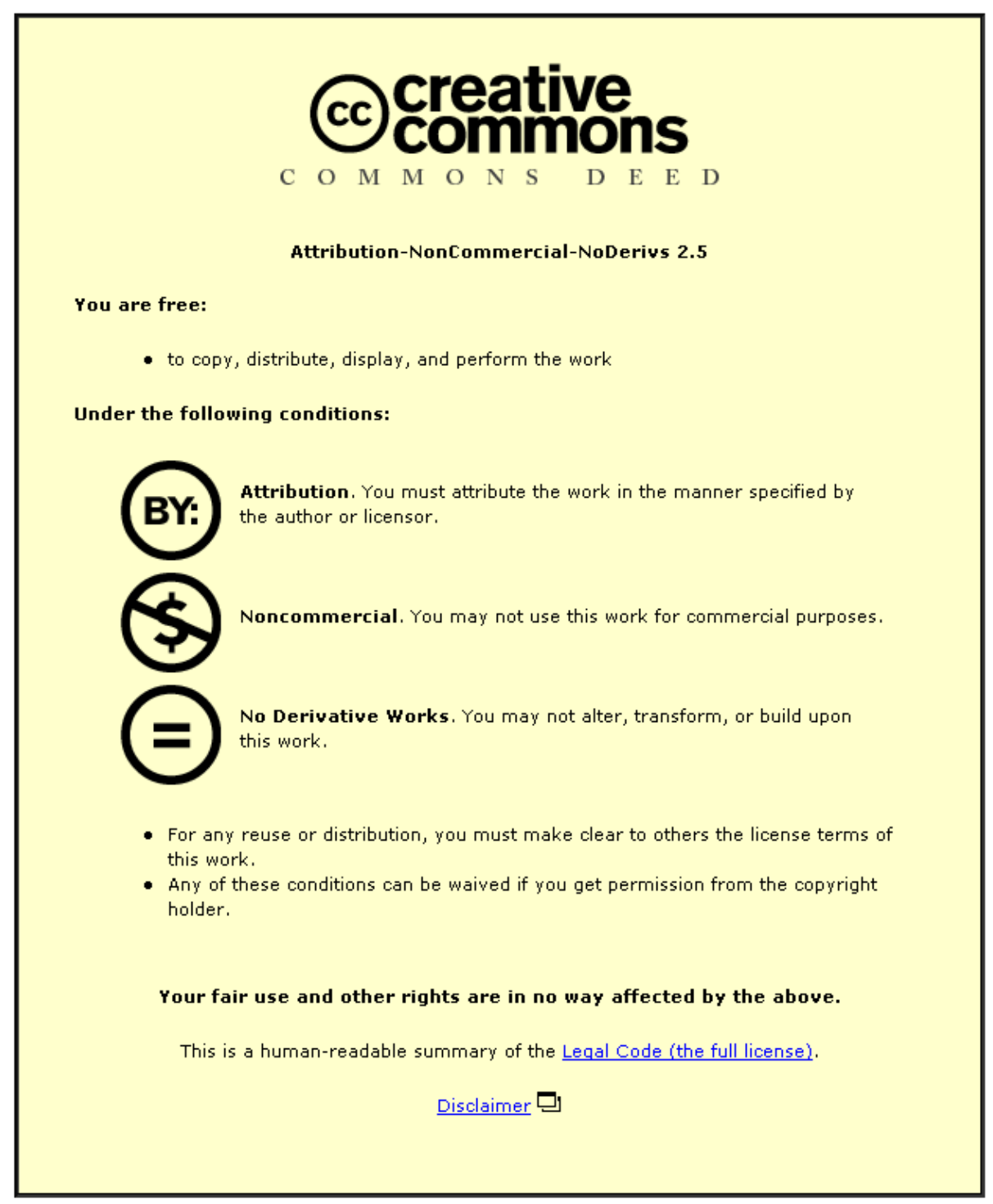

For the full text of this licence, please go to: http://creativecommons.org/licenses/by-nc-nd/2.5/ 


\title{
Diversity and power in the world city network
}

\author{
Peter J. Taylor ${ }^{1}$, David Walker ${ }^{1}$, Gilda Catalano ${ }^{2}$ and Michael Hoyler ${ }^{3}$ \\ ${ }^{1}$ Department of Geography, Loughborough University \\ Loughborough, LE11 3TU \\ UK \\ ${ }^{2}$ Dipartimento di Sociologia e Scienza Politica \\ Universita`degli Studi della Calabria, 87036 Rende (CS) \\ Italy \\ ${ }^{3}$ Geographisches Institut, Universität Heidelberg \\ Berliner Straße 48, 69120 Heidelberg \\ Germany
}




\begin{abstract}
There are three purposes: (1) to illustrate diversity amongst world cities; (2) to show how this reflects/constitutes power relativities between cities; and (3) to place debates on diversity and power on a firm empirical basis. The power of cities is interpreted both as a capacity ('power over') and as a medium ('power to'). World cities are treated as global service centres and the world city network is conceptualised as being 'interlocked' through provision of business and financial services by global firms. The study is primarily empirical and uses a global data set comprising information on 100 global service firms in 123 world cities. Seven different ways of measuring and illustrating power differentials are presented: global network connectivity, banking/finance connectivity, dominant centres, global command centres, regional command centres, high connectivity gateways, and gateways to emerging markets. These categories have been identified before but never specified as comprehensively and rigorously as here. Whereas power as command power is concentrated in the USA, western Europe and Tokyo, network power is much more geographically diffused transcending the old 'North-South divide'. Finally the focus on diversity makes problematic the lazy policy tendency for emulation of a few well-known 'global cities'.
\end{abstract}

\title{
Keywords
}

Gateway city, Global city, Globalization, International financial centres, Network power, World city 


\section{Introduction: diversity and power}

Simply by naming, we homogenise the world. By coining the phrase 'world city', or by devising the concept 'global city', a section of reality is defined through an imposed uniformity. In such exercises researchers invariably provide very good reasons for their particular ordering of the world: the concept brings together a set of objects that epitomise a situation, or they embody a bundle of key processes. And so it was with world/global cities as control centres/strategic places, first in the new international division of labour and latterly within contemporary globalization. The basic test is whether more insight is gained by lumping together the objects than is lost through marginalising their differences. In our view the gains have far outweighed the losses in the case of world/global cities as indicated by the development of a large and vibrant literature on the subject matter. Nevertheless, it is still necessary to take stock regularly of the variety that is hidden by the label. This is the first purpose of this paper: to explore diversity to be found amongst world cities today.

Diversity only implies difference but lurking behind all socially constructed differentiations there is inequality of power. In studies of national urban systems, diversity has been modelled traditionally as city hierarchy but with power relations only implied, hardly ever fully recognised. For instance, in key early texts such as Bourne’s (1975) Urban Systems and Johnston's (1982) The American Urban System power is conspicuous by its absence from the index of both books. There is a major exception within this research tradition in the work of John Friedmann (1978). In his 'The spatial organization of power in the development of urban systems' he investigates the effect of both governmental and economic power on the growth of hierarchical urban systems. This is, of course, particularly pertinent to our concerns here because of this author's subsequent pioneering writings on world cities (Friedmann, 1986). In the latter his earlier concern for the spatial organization of power is transferred from the national scale to a global scale where economic power predominates. Thus he identifies the 'global control functions of cities' that constitute a world city hierarchy. It is the second purpose of this paper to return to Friedmann's original focus on power and to measure contemporary power relativities across world cities. 
This paper is primarily a presentation of empirical findings. This is very important because the world city literature suffers from a serious evidential deficit (Short et al. 1996; Taylor, 1997, 1999). For instance, in the most thorough recent discussion of power among world cities, Allen (1999, Figs 5.3 and 5.5) has had to use Friedmann's original pattern of world city relations from the mid-1980s because no more recent global arrangement of cities was available. Hence although he emphasises ‘frequently shifting patterns of relations' (p. 203) he has to make do with a Cold War situation in which both Moscow and Shanghai are politically excluded from the world city economic hierarchy. The third and final purpose of this paper is to begin to place discussion of worldwide inter-city power relations on a firm empirical basis.

The parameters of this study are as follows. Diversity is limited to economic functions and within these processes we focus on world cities as financial and business service centres. Thus the undoubted cultural power of religious centres such as Jerusalem. Mecca and Rome are not considered and neither are the differences between cities as industrial or retailing centres. This narrowing down of the scope of diversity allows for more elaborate analyses of different forms of power. The first section of our argument deals with the different conceptions of power that we subsequently attempt to elucidate empirically. In the second section we specify the nature of the world city network within which we will measure different powers of cities. This provides the necessary framework to guide data collection and in the third section we describe the unique data set that we have assembled which is the empirical base of this research. There then follow three sections each of which present the findings of analyses using alternative conceptions of power. In the final section we conclude briefly by bringing together our findings on power and by discussing the implications of the diversity revealed for urban policy.

\section{Conceptions of power}

Just as in his national scale research, for Friedmann $(1978,329)$ power is treated as a 'stock of resources' to be used instrumentally as 'power over' others. This is what Allen (1997, 
60) calls 'power as a capacity - a "centred” conception' which he sees as dominating the world cities literature in which cities are centres of control and command (p. 61).

Power as a capacity is just one of the conceptions of power that Allen (1997) identifies. He notes that Sassen's (1991) conception of the 'global city' recognises the limitations of this basic capacity conception (Allen, 1997, 70) but finds little evidence for an alternative conception of power in her work. However Sassen (1994) does treat global cities as 'strategic places' which implies more than simply 'power over'. It seems to us that this is very close to what Allen calls 'power as a medium - a "networked” conception'. Sassen (2000, 48-9) describes a new 'geography of politics' involving 'strategic places ... bound to each other by the dynamics of economic globalization'. There is emerging 'a transnational urban system' with inter-city relations that transcend simple competition (p. 51). The essence of this is 'power to' rather than 'power over', specifically the power to service global capital. This global centring of power in cities is less hierarchical in nature and more networked. In a network, power is much more diffuse as every node has a particular niche that is part of the reproduction of the whole. In other words, complementary relations are more important than competitive ones (Powell, 1990). This means that every city, as a node in an urban network, embodies an incipient power of position.

Because Sassen (1995) focuses on 'centrality', Allen (1999) identifies Castells (1996), with his concept of a 'space of flows', as better describing network power among world cities. For Castells, world cities are not simply places, they are processes, hubs through which flows are articulated with power residing in the flows themselves. Thus Allen (1999, 202-3) sets up an opposition of 'city networks' versus 'networks of cities', that is to say whether the cities 'run' the networks (Sassen) or the networks 'generate' the cities (Castells). This stark contrast is good for highlighting key issues in the literature but, as Allen (1999, 203) admits, 'probably overstates the differences'. We will not choose between these alternative loci of power. In fact, we suspect that this is a theoretical nicety that cannot be resolved empirically. Thus we will not be attempting to distinguish the nodes from the flows in our 
power analyses but we will be focusing on relations between world cities as the basis of their power however conceived.

The approach we adopt is as follows. As an exploratory empirical study we take an eclectic theoretical position with respect to conceptions of power: we incorporate both capacity/command and medium/network conceptions of power in our analyses. We attempt to read power within the world city network as both a capacity expressing hierarchical tendencies and as a collective medium with differences in power expressed through position in the network. This requires precise definition of the network.

\section{An interlocking network}

Our approach to world cities is to consider them as 'global service centres' within an interlocking network. This specification is developed in detail in another paper (Taylor, 2001). The cities are 'interlocked' by the office networks of financial and business service firms. The world city network is linked together by the communications of information, ideas, knowledge and instruction through virtual and material flows within service office networks. Firms such as transnational advertising agencies and inter-jurisdictional law partnerships strive to provide a 'seamless' service for their global clients and in the process have opened offices in cities across the world. The townscapes of many of these cities have come to be typified by the huge tower blocks that house such offices. But these architectural implants are only the visible symptom of world city formation, it is the lessvisible, face-to-face contacts in and around the offices, and the invisible electronic transmissions of information and ideas between offices, that are crucial as world city network formation. Thus the world city network is interpreted as an amalgam of the offices of global service firms and the flows they generate. Through describing the diversity of cities within this network we can begin to identify the different strengths, niches, roles and positions of interlocking world cities. 
This is an unusual network because it has three levels: the network level, the world economy in which the network is constructed; the nodal level, the cities that are the multiple centres of the network; and the sub-nodal level, the service firms that are the agents creating the network. The latter is the key level at which the major processes producing and reproducing the network occur. Thus this is the prime locus of power in the capacity sense: for instance, the headquarters of firms of different sizes have different powers to prosecute a comprehensive global location strategy. But in aggregating this location decision making into a composite interlocking network, we define powers of command and association at the city level. It is at the latter level that we report findings for measuring power relations in this paper.

\section{Global data and inter-city relations}

Given an interlocking system, data must be produced for the 'interlockers', the service firms. Thus, the data requirements for this research are quite straightforward albeit difficult to collect. An interlocking network is defined by a matrix of the objects being interlocked (cities) arrayed against the agents doing the interlocking (firms) (Taylor, 2001).

The information gathering and data production are described in detail in another paper (Taylor et al., 2001a) but the process can be summarised as follows.

- First, a large number of cities (316) was selected is to ensure no cities that could reasonably be deemed 'world cities' are omitted and that we have a reasonable coverage of all world regions.

- Second, the firms were initially selected by using published rankings of firms by size in different sectors. In order to qualify from these lists firms had to have offices in at least 15 different cities and with at least one office in each of the three prime 'globalization arenas', North America, Western Europe and Pacific Asia. This ensures we deal only with firms that can reasonably be described as pursuing a global strategy for their office network: we call such firms 'global service firms'. One hundred firms qualified covering the following sectors: 18 in accountancy, 15 
in advertising, 23 in banking/finance, 11 in insurance, 16 in law, and 17 in management consultancy.

- Third, information on firms was largely derived from their web sites. Two types of information were collected: (1) the size of a firm's presence in a city was recorded (e.g. number of practitioners or number of offices), and (2) the extra-locational functions of offices in a city were noted (e.g. referrals from offices in other cities or regional headquarters). Both types of information were selected because they are directly related to the number of flows generated by a firm within a city to and from its offices in other cities.

- Fourth, these two sets of information were merged to give an indication of the importance of a city within a firm's global strategy, which we term the city's 'service value' to the firm. Given the multifarious range of information from different web sites these data were codified into a simple ordinal scale ranging from 0 to 5 . An ordinary presence (e.g. a typical office) was scored 2, with something lacking the score was reduced to 1 (e.g. an office with no partner present), with exception size the score was increased to 3 and with important extra-locational functions (e.g. a regional headquarters) it was increased to 4, with, finally, cities housing a firm's headquarters scoring 5.

Thus have we constructed a 316 (cities) x 100 (firms) matrix in which each column represents the office network for a given firm over all cities through cells filled by 'service values' showing how important each city is to the firm's overall global strategy. The result is a unique set of 'global data' that enable us to analyse diversity and power amongst world cities in a comprehensive empirical manner.

This analysis uses information about firms to describe inter-city relations. The key feature of our approach is that all analyses are based upon measures of connections describing relations between cities within the network. Only in this way can questions such as the salience of hierarchical tendencies amongst world cities be addressed in a rigorous manner: hierarchies can only be described through relations, not by presenting rankings of cities based upon attributes (Taylor, 1997). But rankings and hierarchy cover only part of our analyses, they are a first step to understand global network in terms of power. We present 
seven different ways of viewing world cities, each of which produces an alternative perspective on the distribution of power among the cities. Thus we show both geographical concentrations and worldwide dispersions of power.

\section{Power as a capacity through connections}

The relative powers of cities are usually presented in tables of rankings by some relevant attribute, such as number of headquarters, size of stock exchange or number of a specialist group of practitioners. This implies the hierarchical model with power measured simply as a quantity. But power is a relation. This does not mean that size is not important, obviously such measures indicate the significance of a city within the world economy, but they do not tell us how well the city is globally connected. A small office with links to more than a hundred offices in other cities may be more important to world city network formation than the large office of a centralised firm with few outside connections. It is how offices are connected within firms across cities that define the network connectivity of cities. It is this latter measure that we use to rank cities.

\section{World city connectivity}

The network connectivity of a city is derived as follows. For every firm present in the city, its service value is multiplied by the firm's service value in every other city. These products are summed. The sum of all product sums for firms in a city defines the network connectivity of the city. This measure is described in more detail in related papers (Taylor, 2001; Taylor et al., 2001a). Obviously a city housing both a lot of firms, and with those firms having large service values, will score very high on this measure. London scores highest and we present the measure for other cities as a proportion of this top score. In Fig. 1 we show 123 cities that have at least one-fifth of London's connectivity. Although not all regions of the world are equally represented on this map, it is noteworthy that all parts have some representation. Africa is the continent with by far the least cities but even here there are six cities to be found covering the main regions (north: Cairo and Casablanca; west: 
Lagos; east: Nairobi; and south: Johannesburg and Cape Town). This is a world city network with a global reach and we use this set of cities in all subsequent analyses.

The twenty cities with the highest levels of global network connectivity are shown in Fig. 2. These have been divided into three levels. First we designate London and New York as 'global cities' because there is a sizeable gap between their level of connectivity and that of all other cities. With London scoring 1.00, New York is only just behind with 0.98. The next highest score is 0.71 (Hong Kong) and from this level onwards there is a relatively smooth gradation of declining scores. Thus the other two categories use arbitrary cut off points (0.59 and 0.48$)$ to show the rest of the top ten and top twenty respectively. The first thing to notice about this map is that the world wide spread remains, even when we focus upon just the highly connected cities. Although Western Europe dominates the pattern with 8 cities, there are 5 from North America and 4 from Pacific Asia. In addition both Latin America and Australia are represented. This distribution is consistent with the pioneering work of both John Friedmann (in which the top world cities are identified in both core and semi-peripheral regions; Friedmann, 1986, Table 1) and Sassen $(2000,49)$ for whom 'the worldwide grid of global cities ... cuts across ... the old North-South divide'.

\section{International financial centre connectivity}

There is one clear difference between Fig. 2 and many common conceptions of the apex of the world city hierarchy where Tokyo is grouped with London and New York (Sassen, 1991; Friedmann, 1995). In terms of our global network connectivity Tokyo ranks only fifth behind Hong Kong and Paris. However, for Friedmann, Tokyo’s pre-eminence is identified as 'global financial articulation', that is to say he is not necessarily considering Tokyo a top three city for more general world city status. We can illustrate his argument by computing connectivity using only the 23 banking/finance firms in our data to produce a ranking of international financial centres (IFCs). The resulting top 20 cities in terms of global financial connectivity are shown in Fig. 3. In this case we have grouped Tokyo (0.94) with London (1.00) and New York (0.98) as 'global IFCs'. Other cities that rise in ranking are Frankfurt and Madrid, while Los Angeles and Milan drop. Regionally, the main feature is the rise of Pacific Asia which overtakes Western Europe with most representation 
(7 cities compared to 6). This is consistent with other analyses that show Pacific Asia to be the globalization arena particularly based upon banking/finance services (Taylor et al., 2001b, 2001c).

Conclusion on connectivity: if the power of a world city is a function of its connectivity with other cities, then the tendency is for this power to be widely diffused across the world. If financial linkages are thought to be especially important to contemporary globalization, then the evidence here suggests an even greater spread at least in the upper echelons of IFCs throughout Pacific Asia.

\section{Power as domination and command}

Ranking by connectivity is an indirect way of showing the power of a city in the sense of its importance in the network, but it does not address application of power. This instrumental power was crucial to Friedmann's (1986) conception of world cities, where he famously refers to 'control and command centres' and we explore this idea empirically in two ways, which we term domination and control. Both concepts are based upon asymmetric relations: we take domination to be an expression of size differences, and command to involve organisation involving direction from above.

\section{Dominant centres}

As we have specified above, in deriving the network connectivity of a city, each firm's service value for the city is multiplied in turn with that firm's service value in all other cities. For each city, these products can be classified into three types. Where the city in question has the higher service value, we can refer to this as a dominant connection; where it has the lower value it is a subordinate connection; otherwise, where both values are the same, there is neither dominance nor subordination. From this we can decompose the network connectivity of a city into three parts: connectivity-through-dominance, connectivity-through-subordination, and neutral connectivity. In such an analysis only 34 of our cities have more connectivity-through-dominance than connectivity-through- 
subordination. These are shown in Fig. 4, where they are differentiated by the ratio between the two types of connectivity. Once again London and New York stand out with 17.5 and 14.9 times more domination than subordination in their network connectivities, respectively. These are designated 'mega' dominant centres given that the next highest ratio is only 3.5. There are six cities with ratios from 2.5 to 3.5 and they are designated 'major' dominant centres in Fig. 4. Given their overall importance in connectivity it is not surprising that Hong Kong, Paris, Tokyo and Chicago appear in this category but Frankfurt and Miami are not expected. Frankfurt actually ranks fourth, a position which is far above its usual world city ranking. This suggests its role as EU financial centre is reflected as major dominance. Miami is famously the world city for Latin America and the Caribbean and this produces its major dominance status here (Brown et al., 2001). The cut off point between 'medium' and 'minor' dominant centres is 1.5. The most notable feature of the distribution of cities in Fig. 4 compared to Fig. 3 is the relative unimportance of Pacific Asia, which has only 5 dominant centres compared to 14 for Western Europe and 11 for North America.

\section{Global command centres}

The demise of Pacific Asia as a region of powerful world cities is further accentuated if we focus just on cities that have service values of 5, which include all headquarter functions. There are only 21 cities that house the headquarters of our 100 global service firms and we term them command centres. These are shown in Fig. 5 and are differentiated in terms of the total product of service values that includes a city's scores of 5. Once again London and New York stand out with values of 21920 and 17649 respectively and the third place is far behind (Chicago with 5145). These two cities are the 'mega' command centres of the world city network. There are two other cities with command products above 4000 and with Chicago are designated 'major' command centres. The boundary point between 'medium' and 'minor' is 1000 . The key feature of this pattern is the total concentration in Western Europe and North America, with the sole exception of Tokyo as a major command centre. On this occasion there are as many cities represented in North America as in Western Europe (10 each). This is a stark picture of where the direct instrumental power lies within 
the world city network. Globalization may be a worldwide phenomenon, but its command centres are most certainly not so distributed.

\section{Regional command centres}

The degree of power exercised by headquarter offices will obviously vary by firm depending upon how it organises its decision making processes (Dicken, 1998). Some firms are very 'vertical' in their structures whereas others are more 'horizontal'. For instance, the law firm White \& Case concentrates its decision-making in its New York headquarters, whereas rivals Baker \& McKenzie is very decentralised and refuses to call its central 'administrative office' in Chicago its headquarters (Beaverstock et al., 2000). Decentralisation often takes a geographical form, with particular offices chosen to be 'regional headquarters'. The operative word here is 'chosen'. Generally the main headquarters reflects a firm's origins and it is usual for the city where a firm began to continue to house its main decision-making functions. In contrast, regional headquarters are designated as part of a firm's spatial strategy.

Most of the global service firms in our data do not have designated regional offices but there are enough that do to show a clear pattern of spatial organisation. As part of the data collection, we identified all offices that had 'extra-locational functions' which could be national, transnational or regional. Here we concentrate upon the 118 transnational and regional offices. Ignoring cities with just one such office (which just reflects particularities of a single firm), cities with transnational and regional offices are shown in Fig. 6. London has by far the most of such offices (25), often with responsibilities covering Europe, the Middle East and Africa (EMEA). Defining 'major' regional world cities as those with at least 10 such offices, there are three other cities that qualify: Hong Kong (151/2, the 1/2 indicating shared responsibility), New York (13) and Miami (11). There are also three cities designated 'medium' regional world cities with from 7 to 9 such offices: Singapore (9), Tokyo (71/2) and Sao Paulo (71/2). These results are very similar to those given in Taylor (2000), but are based upon much more evidence. The remaining cities on Fig. 6 have from 2 to 4 transnational or regional offices. Note that with this form of organisation, there is a diffusion of some instrumental power out from North America and Western Europe. Pacific 
Asian cities reappear beyond Tokyo and there are three cities servicing 'southern regions' (São Paulo, Johannesburg and Manama). However, there are still extra-regional headquarters, notably London for the Middle East/Africa and Miami for Caribbean/Latin America where 'northern' power impinges directly into the 'southern' continents, even at this regional scale.

Conclusion on domination and command: from this power perspective, Sassen's notion of global cities transcending the North-South divide seems a trifle sanguin; globalization begins to look very ‘western' as soon as we look at direct expressions of power.

\section{Power through the network: the places to be}

The existence of infrastructural power through the network is clearly suggested by the major discrepancy between the network connectivity rankings and the command functions. Whereas Hong Kong ranks third in global connectivity, it has no global command functions. This means that despite the latter, Hong Kong has attracted large numbers of service firms because of its position in the network. It is the prime location for firms to service clients in the growing Chinese market. Thus for many global strategies, Hong Kong is a place where one has to be. Hong Kong is the node in the network where specialist knowledge on abilities and possibilities in the Chinese market intersect with global flows of information and ideas. Places such as this, where firms need to be to service their clients, embody a network power through their positioning.

Traditionally such 'necessary regional cities' have been called gateway cities (Johnston, 1982) and this terminology has entered the world city literature (Short, et al.. 2000). Quite simply, the world economy does not consist of an undifferentiated market, but congeries of regional and national markets, each with their own particularities, that have to be translated through gateway cities. We define gateway cities in two different ways, drawing upon previous analyses. 


\section{High connectivity gateways}

The simplest way to define the places where many firms decide they 'have to be' is to look beyond the 21 command centres (Fig. 5). In Fig. 7 the top 35 cities without command functions have been selected in terms of their high global network connectivity. As we have already noted, Hong Kong ranks number one here, since it is the third most connected world city even though it has no command functions. These highly connected noncommand centres are divided into three levels, in terms of their network connectivity, in Fig. 7. At the highest level, the cities each relate to a major national economy outside the top five economies (USA, Japan, Germany, France, UK): as well as Hong Kong/China there is Milan/Italy, Toronto/Canada, Madrid/Spain, Sydney/Australia and São Paulo/Brazil plus the regional Singapore/ASEAN (Association of South East Asian Nations). Cities at the next level have similar relations: Mexico City/Mexico, Buenos Aires/Argentina, Mumbai/India, Taipei/Taiwan, plus the regional Miami/Caribbean-Latin America. These are all cities attending to gateway functions for national and regional markets: they are the classic gateway cities of contemporary globalization.

\section{Gateways to emerging markets}

An alternative approach is to look at connectivity-through-subordination. This is the obverse of searching for dominant cities (Fig. 4). Being based upon the subordinate relations, we might be tempted to see these cities only as 'dependent' within a hierarchy. But in network relations, where all cities are dependent on all others by definition, this subordination does not equal powerlessness. Rather we interpret these cities as 'emerging centres', new strategic places where firms from elsewhere choose to expand their geographical reach. On Fig. 8 we show the 31 cities with connectivity-throughsubordination levels above 5000, selecting out those with levels above 6000 as 'major' emerging centres. By definition, all these cities have few important offices - global or regional - but they house large numbers of ordinary offices. This suggests the cities each have a particular attraction to many global service firms who have to have a presence in the city. Beijing has the highest connectivity-through-subordination, followed closely by Moscow. These are obviously capital cities of countries with large 'emerging' markets. Other major emerging centres, Seoul, Caracas and São Paulo, are also leading cities in 
important emerging markets. Zürich, Europe’s only major emerging centre, is a special case relating to the country's success as a 'neutral' venue (especially in banking where it is more a gatekeeper than a gateway) within the world economy. Beyond these major emerging centres the other cities in Fig. 8 are quite similar in nature, being leading cities in emerging markets outside, or on the fringe of the core of the world economy.

Conclusion for network power: there are cities that are important strategic nodes within the world city network but which have no command power. In this configuration of power, the world city network does appear to transcend the North-South divide power differentials to a measurable degree.

\section{Conclusion: power and diversity}

Although it operates as a network, there is no doubt that there are hierarchical tendencies within the relations between world cities. In other words, in the world city network all cities are equal but some are more equal than others. But the power differentials in the world city network are not easily discerned. Power takes several forms and we have to be careful not to give precedence to the transparent - 'command and control centres' - over more opaque network power. With the help of a unique set of data describing an interlocking world city network, we have been able to unravel some of the mysteries of the configuration of power in the contemporary world city network. The results are summarised in Table 1, where the leading cities in Figs 2 through 8 are identified. These are the 31 most powerful cities in contemporary globalization, as measured in seven different ways. However we should not forget the other 92 cities depicted in Fig. 1; although not having major positions of power they are still well connected and have their own particular niches within the network. As well as the smaller regional command centres such as Johannesburg, smaller national gateways such as Santiago, and off-shore financial centres, such as Hamilton (Bermuda), there are many 'evasive cities' in the world city network within Western countries that do not register in our analysis, such as Denver, Manchester and Cologne. Clearly, we are only 
at the stage of preliminary exploration in our understanding of the configuration of power in the world city network.

Finally, looking at Table 1 as a description of the diversity amongst world cities - the different ranks, roles, niches and positions of cities within the network - we can note the important implications for city governments and local economic alliances that are attempting to manoeuvre their cities through the upheavals of contemporary globalization. There are two main points that arise. First, there is a dilemma confronting all policymaking in world cities, especially in semi-peripheral and peripheral zones. Our analysis has emphasised the incipient power that ensues from being part of a network, but such configurations are not inherently stable. Hence Allen and his colleagues $(1999,4)$ note the vulnerability of such cities, which is something that our cross-sectional analysis does not treat. However, the dilemma is that a policy of exclusion from such global connectivities will likely stultify economic growth, and exacerbate economic polarisation: at least being within the networks allows the possibility to negotiate inclusion (Allen et al. 1999, 5). And this is where the network powers that we have uncovered may operate to provide negotiating space for what Pryke (1999) calls 'cities of neo-liberalism'.

Second, assuming city governors opt to be part of the world city network, there is the question of how they should play their hand. Unfortunately, one of the effects of setting up categories 'world city' and 'global city' has been to create exemplars to imitate as success models; a process of emulation has been put in place. This has had a profound impact world wide as city governments have pursued policies of translation and replication across all continents. One implication of emphasising diversity among world cities is that emulation becomes problematic - the future urban world will not consist of many 'little New Yorks' and 'mini-Londons' (Taylor et al., 2001a). This position is entirely consistent with Krätke’s (1999) critique of Berlin's stalled policy of developing the city as a 'service metropolis'. That is why we argue that instead of pursuing policies to improve a city's ranking by adding to their stock of functions and practices, cities need to attend to their position within a network of cities (Taylor, 2001; Beaverstock et al., 2002). Policy needs to be focused 
upon connections and linkages within an overall framework of many networks. The old adage that 'no city is an island' has never been truer than today.

\section{Acknowledgement}

We acknowledge the support of ESRC. The paper is based upon research conducted as part of the project "World city network formation in a space of flows".

\section{References}

Allen, J (1997) Economies of power and space. In: Lee, R and Wills, J (Eds.), Geographies of Economies, Arnold, London, pp.59-70.

Allen, J (1999) Cities of power and influence: settled formations. In: Allen, J, Massey, D and Pryke, M (Eds.), Unsettling Cities, Routledge, London, pp. 181-228.

Allen, J, Massey, D and Pryke, M (1999) Introduction. In: Allen, J, Massey, D and Pryke, M (Eds.), Unsettling Cities, Routledge, London, pp. 1-6.

Beaverstock, J V, Smith, R G and Taylor P J (2000) Geographies of globalization: United States law firms in world cities. Urban Geography 21 (2), 95-120.

Beaverstock, J V, Doel, M A, Hubbard, P J and Taylor, P J (2002) Attending to the world: competition, co-operation and connectivity in the world city network. Global Networks 2 (2), 111-132.

Bourne, L S (1975) Urban Systems, Clarendon Press, Oxford 
Brown, E D, Catalano, G and Taylor, P J (2001) Beyond world cities: Central America in a global space of flows. Area (forthcoming)

Castells, M (1996) The Rise of Network Society, Oxford, Blackwell.

Dicken, P (1998) Global Shift, Paul Chapman, London

Friedmann, J (1978) The spatial organization of power in the development of urban systems. In: Bourne, L S and Simmons, J W (Eds.) Systems of Cities, Oxford University Press, New York, pp. 328-340.

Friedmann, J (1986) The world city hypothesis. Development and Change 17 (1), 69-83.

Friedmann, J (1995) Where we stand: a decade of world city research. In: Knox, P L and Taylor, P J (Eds), World Cities in a World-System, Cambridge University Press, Cambridge, pp. 21-47.

Johnston, R J (1982) The American Urban System, Longman, London

Krätke, S (1999) Berlin's regional economy in the 1990s: structural adjustment or 'openended’ structural break? European Urban and Regional Studies 6 (4), 323-338.

Powell, W W (1990) Neither market nor hierarchy: network forms of organization. Research in Organizational Behavior 12, 295-336.

Pryke, M (1999) City rhythms: neo-liberalism and the developing world. In: Allen, J, Massey, D and Pryke, M (Eds.), Unsettling Cities, Routledge, London, pp. 229-270.

Sassen, S (1991) The Global City, Princeton University Press, Princeton, NJ.

Sassen, S (1994) Cities in a World Economy, Pine Forge, Thousand Oaks. 
Sassen, S (1995) On concentration and centrality in the global city. In: Knox, P L and Taylor, P J (Eds.) World Cities in a World-System. Cambridge, Cambridge University Press, pp. 63-78.

Sassen, S (2000) The global city; strategic site/new frontier. In: Isin, E F (Ed.) Democracy, Citizenship and the Global City, Routledge, New York, pp. 48-61.

Short, J R, Kim, Y, Kuss, M and Wells, H (1996) The dirty little secret of world cities research. International Journal of Urban and Regional Research 20, 697-717.

Short, J R, Breitbach, C, Buckman, S and Essex, J (2000) From world cities to gateway cities. City 4, 317-340.

Taylor. P J (1997) Hierarchical tendencies amongst world cities: a global research proposal. Cities 14 (6), 323-332.

Taylor, P J (1999) 'So-called world cities: the evidential structure within a literature. Environment and Planning A 31, 1901-1904.

Taylor, P J (2000) World cities and territorial states under conditions of contemporary globalization. Political Geography 19, 5-32.

Taylor, P J (2001) Specification of the world city network. Geographical Analysis 33 (2), 181-194.

Taylor, P J, Catalano, G and Walker D R F (2001a) Measurement of the world city network. GaWC Research Bulletin No 43.

Taylor, P J, Catalano, G and Walker D R F (2001b) Exploratory analysis of the world city network. GaWC Research Bulletin No 50. 
Taylor, P J, Catalano, G and Walker D R F (2001c) Multiple globalizations: regional, hierarchical and sectoral articulations of global business services through world cities. GaWC Research Bulletin No 55. 
Table 1 Powerful cities

\begin{tabular}{|c|c|c|c|c|c|c|c|}
\hline CITY & $\begin{array}{l}\text { Highly } \\
\text { connected } \\
\text { world cities }\end{array}$ & $\begin{array}{l}\text { Highly } \\
\text { connected } \\
\text { IFCs }\end{array}$ & $\begin{array}{l}\text { Dominant } \\
\text { centres }\end{array}$ & $\begin{array}{l}\text { Global } \\
\text { command } \\
\text { centres }\end{array}$ & $\begin{array}{l}\text { Regional } \\
\text { command } \\
\text { centres }\end{array}$ & $\begin{array}{l}\text { Highly } \\
\text { connected } \\
\text { gateway } \\
\text { cities }\end{array}$ & $\begin{array}{l}\text { Emerging } \\
\text { city } \\
\text { gateways }\end{array}$ \\
\hline Amsterdam & & & & $\mathrm{X}$ & & & \\
\hline Beijing & & & & & & & $\mathrm{X}$ \\
\hline Brussels & & & & $\mathrm{X}$ & & & \\
\hline Boston & & & & $X$ & & & \\
\hline Buenos Aires & & & & & & $X$ & \\
\hline Caracas & & & & & & & $x$ \\
\hline Chicago & $X$ & $x$ & $X$ & $\mathrm{X}$ & & & \\
\hline Frankfurt & & $x$ & $\mathrm{X}$ & $\mathrm{X}$ & & & \\
\hline Hong Kong & $\mathrm{X}$ & $\mathrm{X}$ & $\mathrm{X}$ & & $\mathrm{X}$ & $\mathrm{X}$ & \\
\hline Jakarta & & $x$ & & & & $X$ & \\
\hline Kuala Lumpur & & & & & & $x$ & \\
\hline London & $x$ & $\mathrm{X}$ & $\mathrm{X}$ & $\mathrm{X}$ & $x$ & & \\
\hline Los Angeles & $x$ & & & & & & \\
\hline Madrid & & $\mathrm{X}$ & & & & $x$ & \\
\hline Melbourne & & & & & & $X$ & \\
\hline Mexico City & & & & & & $x$ & \\
\hline Miami & & & & & $X$ & $\mathrm{X}$ & \\
\hline Milan & $x$ & & & & & $\mathrm{X}$ & \\
\hline Moscow & & & & & & & $x$ \\
\hline Mumbai & & & & & & $X$ & \\
\hline New York & $\mathrm{X}$ & $\mathrm{X}$ & $\mathrm{X}$ & $\mathrm{X}$ & $x$ & & \\
\hline Paris & $x$ & $\mathrm{X}$ & $X$ & $X$ & & & \\
\hline São Paulo & & & & & $X$ & $X$ & $\mathrm{X}$ \\
\hline Seoul & & & & & & & $\mathrm{X}$ \\
\hline Singapore & $\mathrm{X}$ & $x$ & & & $x$ & $\mathrm{X}$ & \\
\hline Sydney & & & & & & $\mathrm{X}$ & \\
\hline Taipei & & & & & & $x$ & \\
\hline Tokyo & $\mathrm{X}$ & $x$ & $x$ & $\mathrm{X}$ & $x$ & & \\
\hline Toronto & $x$ & & & & & $x$ & \\
\hline $\begin{array}{l}\text { Washington } \\
\text { DC }\end{array}$ & & & & $X$ & & & \\
\hline Zürich & & & & $x$ & & & $x$ \\
\hline
\end{tabular}

$\mathrm{X}$ shows presence in the top or top two categories in Figs 2-8 
Figure 1 The world city archipelago defined by network connectivity

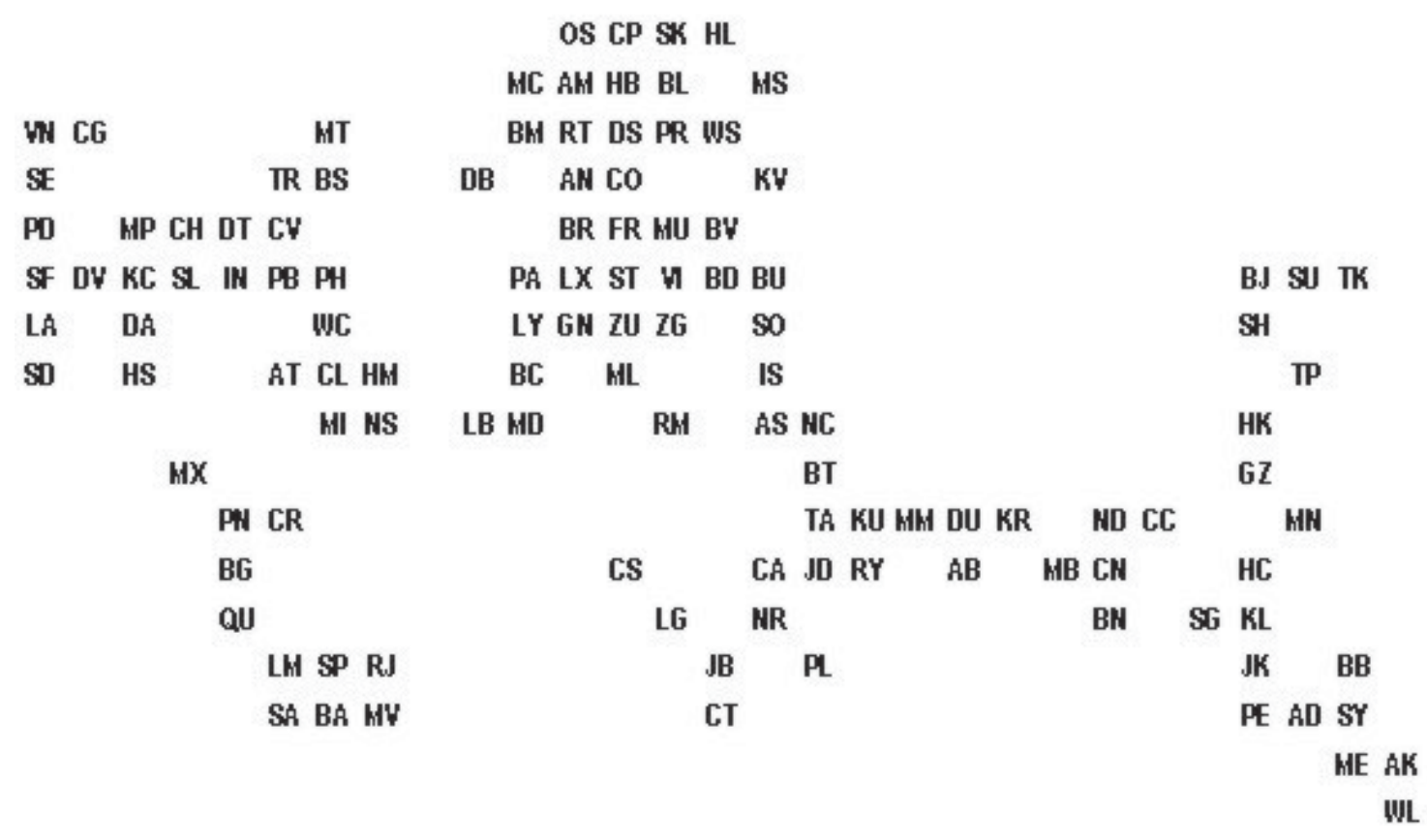

This cartogram places cities in their approximate relative geographical positions. The codes for cities are: AB Abu Dubai; AD Adelaide; AK Auckland; AM Amsterdam; AS Athens; AT Atlanta; AN Antwerp; BA Buenos Aires; BB Brisbane; BC Barcelona; BD Budapest; BG Bogota; BJ Beijing; BK Bangkok; BL Berlin; BM Birmingham; BN Bangalore; BR Brussels; BS Boston; BT Beirut; BU Bucharest; BV Bratislava; CA Cairo; CC Calcutta; CG Calgary; CH Chicago; CL Charlotte; CN Chennai; CO Cologne; CP Copenhagen; CR Caracas; CS Casablanca; CT Cape Town; CV Cleveland; DA Dallas; DB Dublin; DS Dusseldorf; DT Detroit; DU Dubai; DV Denver; FR Frankfurt; GN Geneva; GZ Guangzhou; HB Hamburg; HC Ho Chi Minh City; HK Hong Kong; HL Helsinki; HM Hamilton(Bermuda); HS Houston; IN Indianapolis; IS Istanbul; JB Johannesburg; JD Jeddah; JK Jakarta; KC Kansas City; KL Kuala Lumpur; KR Karachi; KU Kuwait; KV Kiev; LA Los Angeles; LB Lisbon; LG Lagos; LM Lima; LN London; LX Luxembourg; LY Lyons; MB Mumbai; MC Manchester; MD Madrid; ME Melbourne; MI Miami; ML Milan; MM Manama; MN Manila; MP Minneapolis; MS Moscow; MT Montreal; MU Munich; MV Montevideo; MX Mexico City; NC Nicosia; ND New Delhi; NR Nairobi; NS Nassau; NY New York; OS Oslo; PA Paris; PB Pittsburgh; PD Portland; PE Perth; PH Philadelphia; PL Port Louis; PN Panama City; PR Prague; QU Quito; RJ Rio de Janeiro; RM Rome; RT Rotterdam; RY Riyadh; SA Santiago; SD San Diego; SE Seattle; SF San Francisco; SG Singapore; SH Shanghai; SK Stockholm; SL St Louis; SO Sofia; SP Sao Paulo; ST Stuttgart; SU Seoul; SY Sydney; TA Tel Aviv; TP Taipei; TR Toronto; VI Vienna; VN Vancouver; WC Washington DC; WL Wellington; WS Warsaw; ZG Zagreb; ZU Zurich 
Figure 2 The most connected world cities

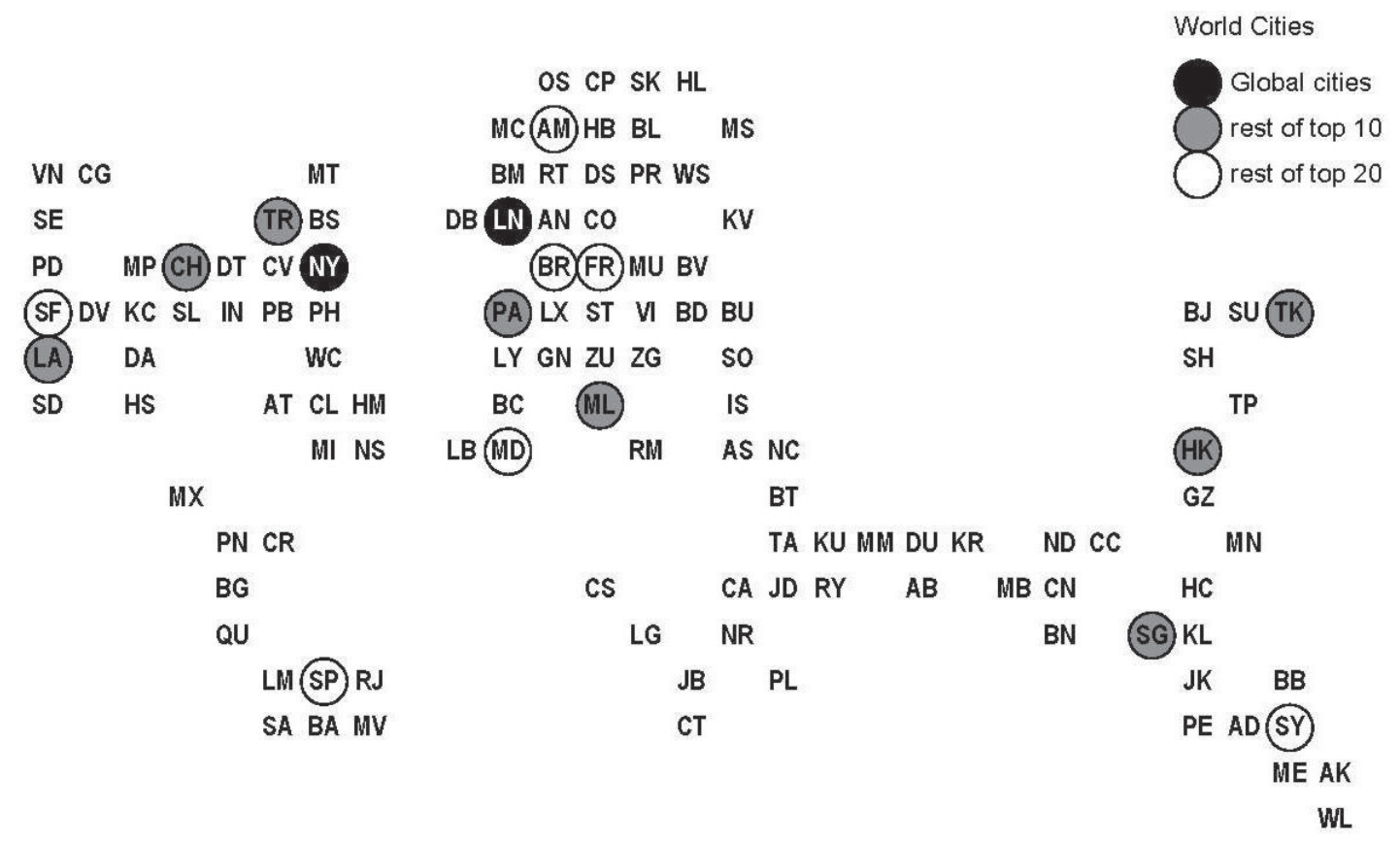

Figure 3 The most connected international financial centres

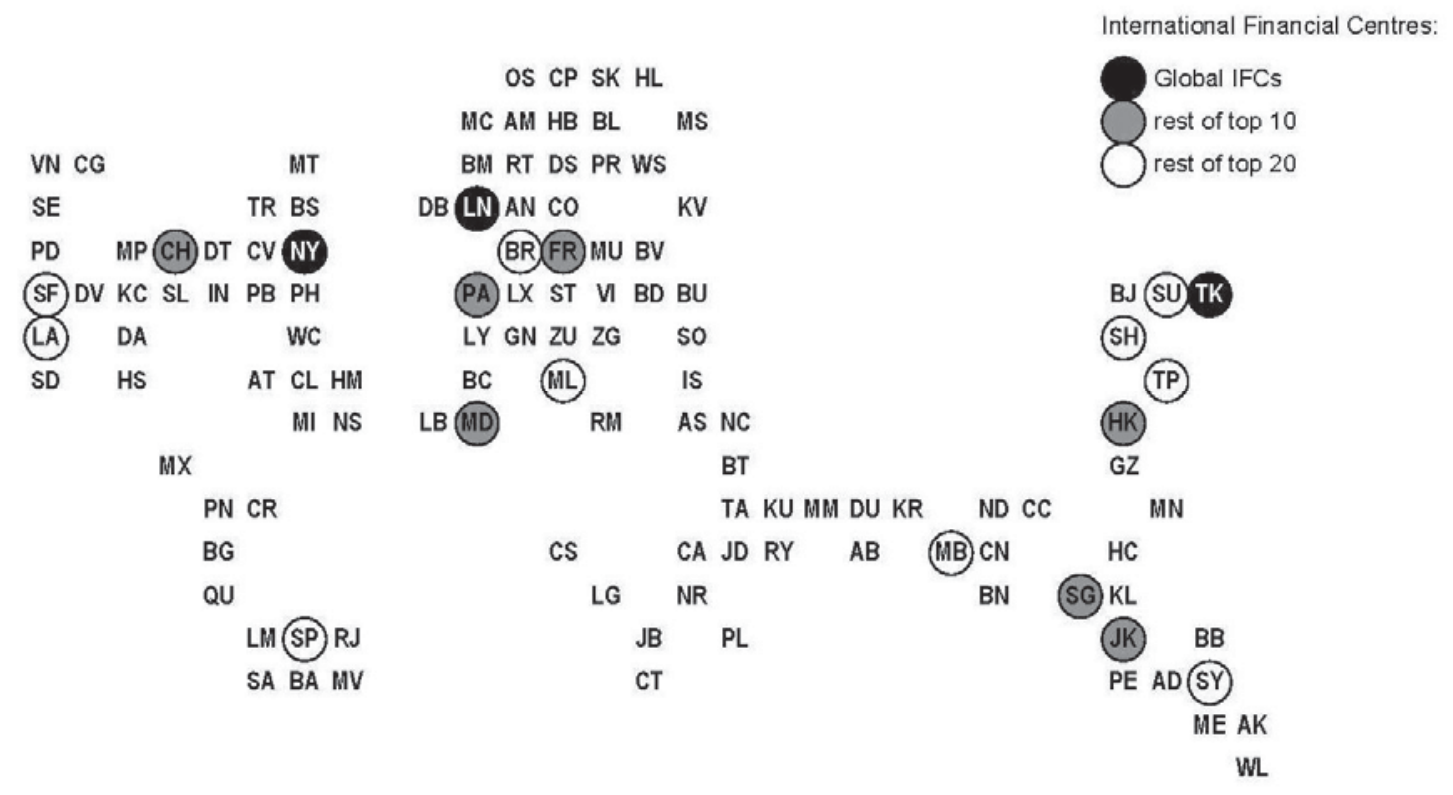


Figure 4 Dominant centres

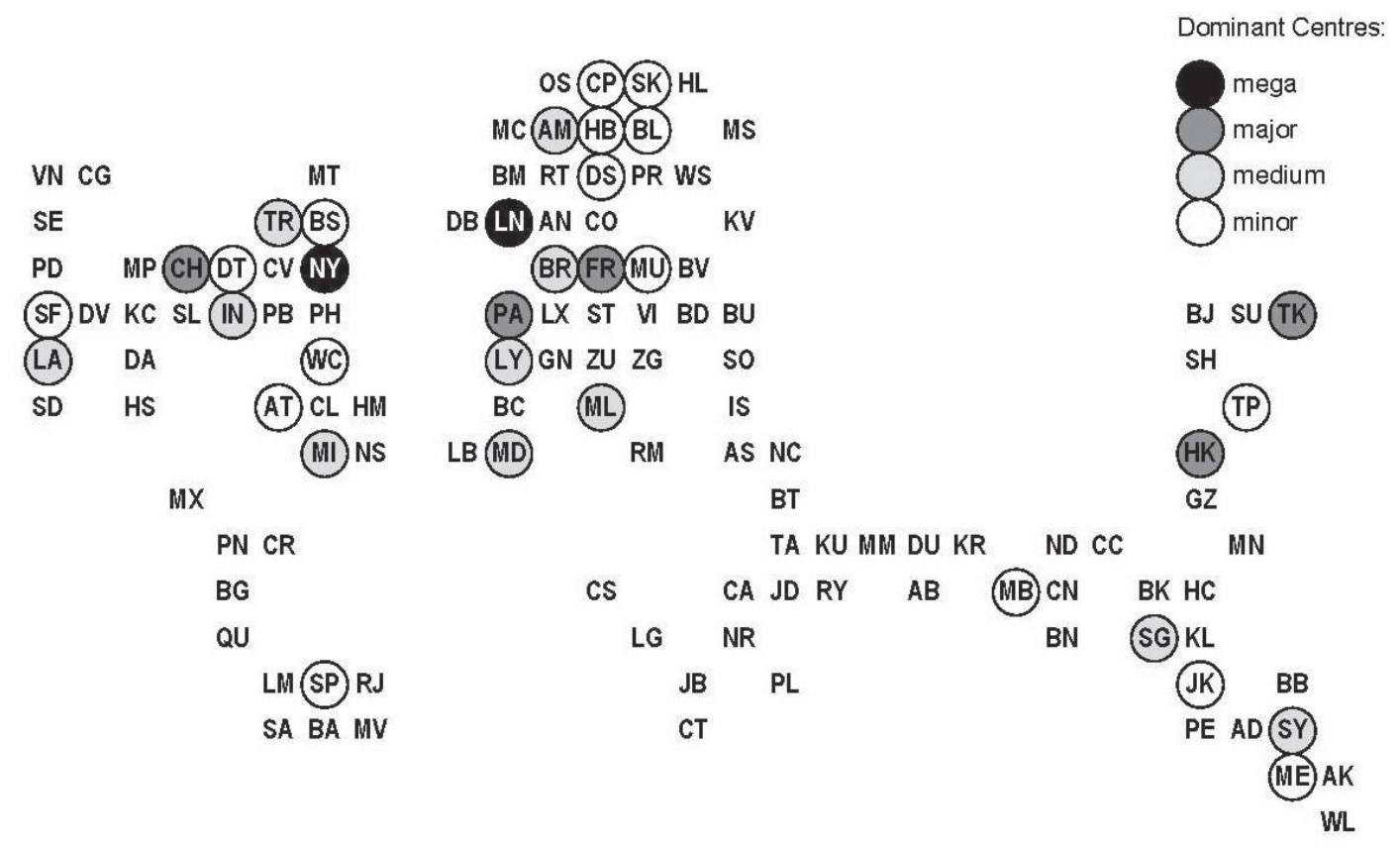

Figure 5 Global command centres

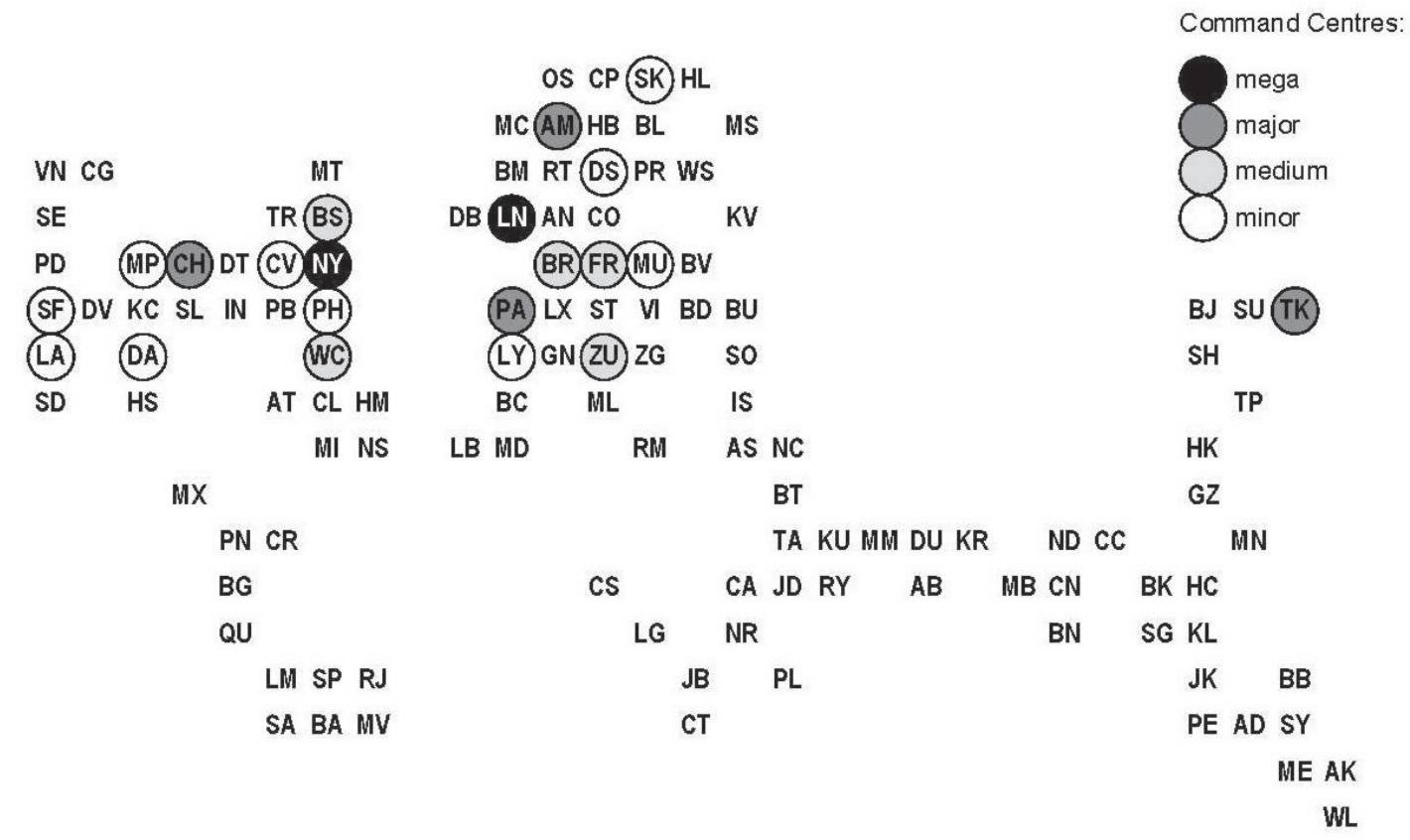


Figure 6 Regional command centres

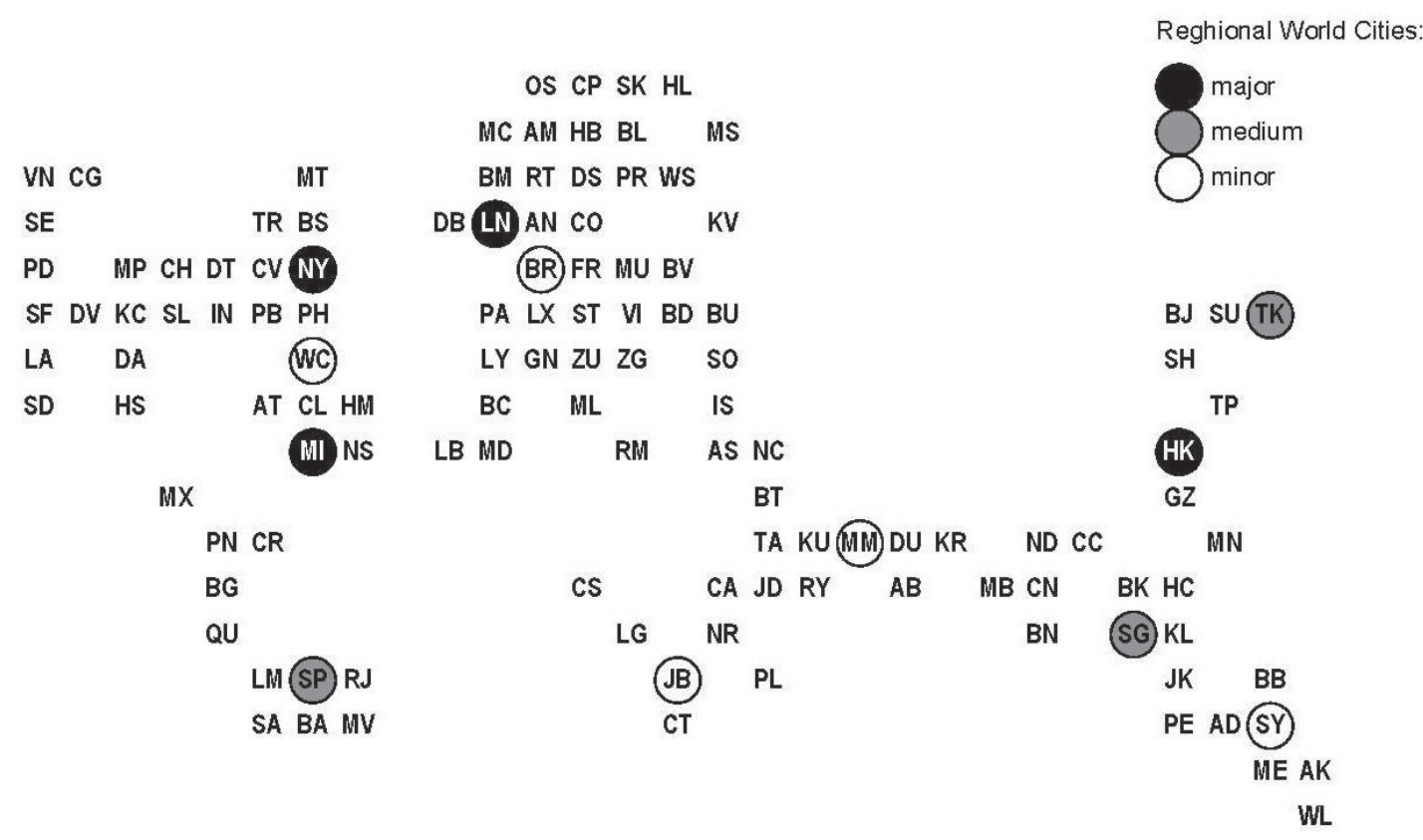

Figure 7 High connectivity gateways

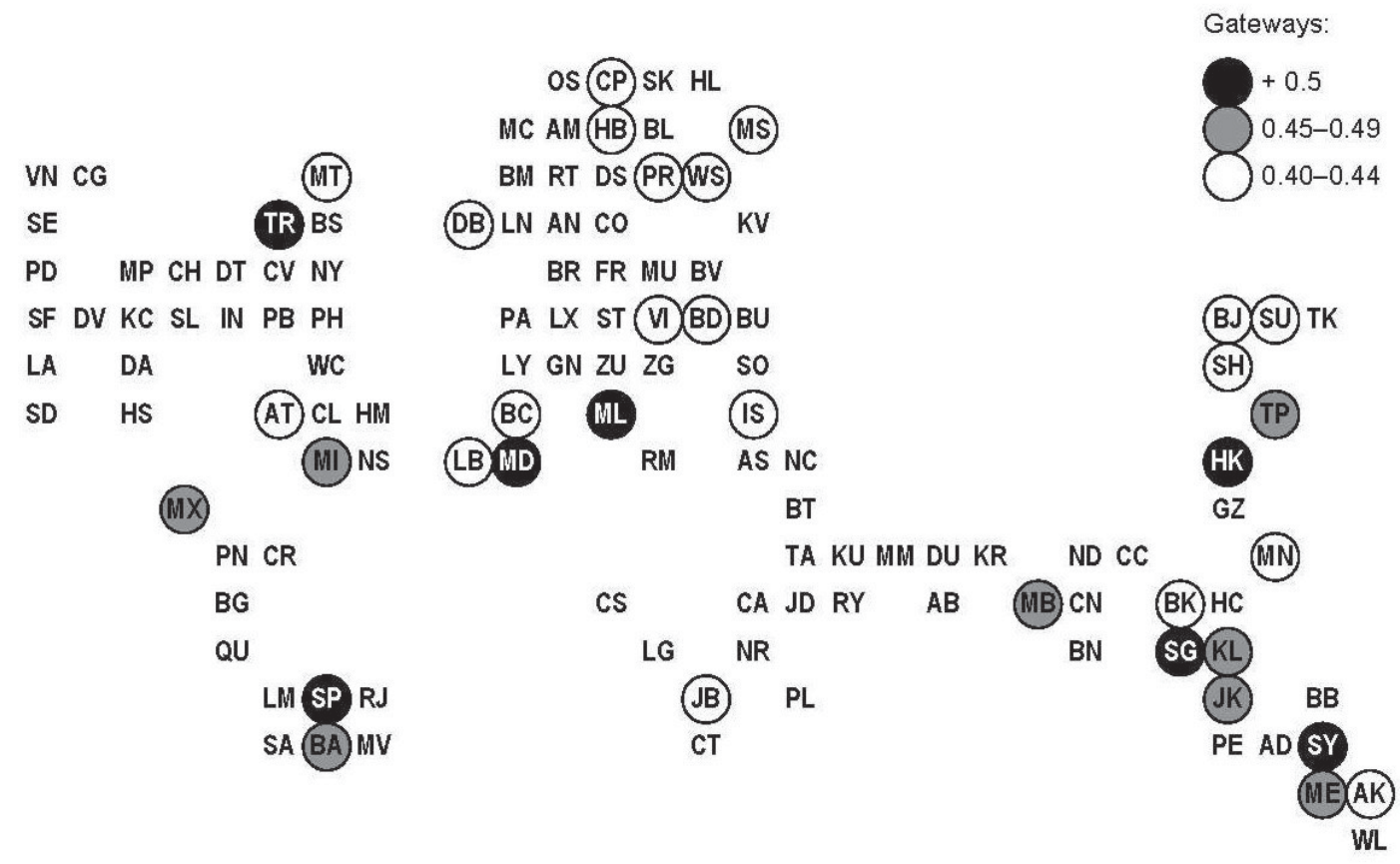


Figure 8 Emerging centres

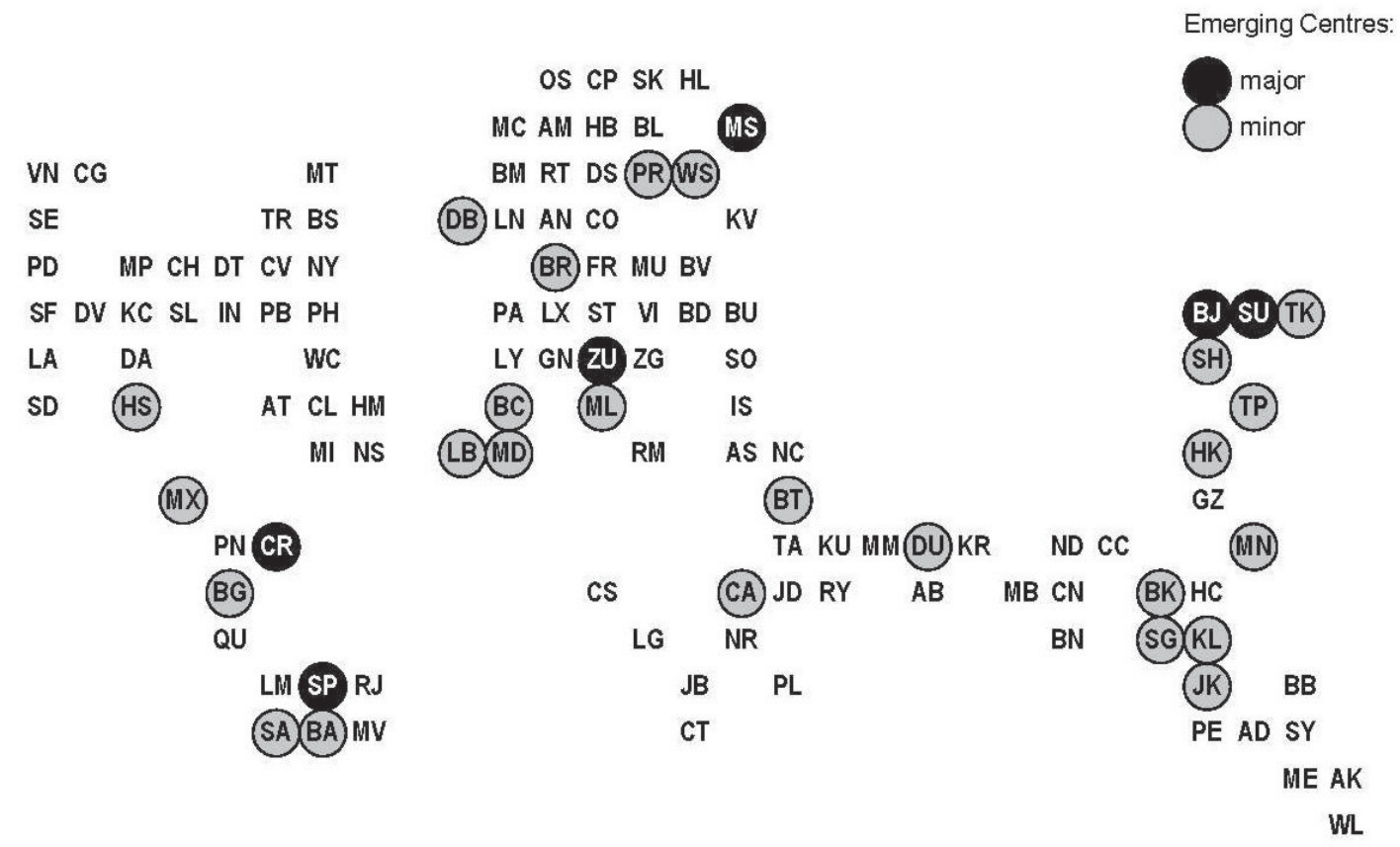

